\title{
Virgin Coconut Oil: Remedial Effects on Renal Dysfunction in Diabetic Rats
}

\author{
A. M. Akinnuga, ${ }^{1}$ S. O. Jeje, ${ }^{1}$ O. Bamidele, ${ }^{2}$ E. E. Amaku, ${ }^{1}$ F. O. Otogo, ${ }^{1}$ and V. E. Sunday ${ }^{1}$ \\ ${ }^{1}$ Department of Human Physiology, Cross River University of Technology, Okuku Campus, Ogoja, Cross River State, Nigeria \\ ${ }^{2}$ Department of Physiology, Bowen University, Iwo, Osun State, Nigeria
}

Correspondence should be addressed to A. M. Akinnuga; akinnugaakinjide@yahoo.com

Received 25 May 2014; Accepted 24 June 2014; Published 9 July 2014

Academic Editor: Gary Lopaschuk

Copyright (C) 2014 A. M. Akinnuga et al. This is an open access article distributed under the Creative Commons Attribution License, which permits unrestricted use, distribution, and reproduction in any medium, provided the original work is properly cited.

Renal dysfunction is now a prevalent complication of diabetes mellitus. Therefore, this study was carried out to evaluate the remedial effects of virgin coconut oil (VCO) on renal dysfunction in diabetic rats. Fifteen albino Wistar rats were divided into 3 groups that comprise normal control group (Group I) and diabetic control group (Group II) fed with normal rat chows and a diabetic test group (Group III) fed with 10\% VCO diet. Group II and Group III were made diabetic by single intraperitoneal injection of $150 \mathrm{mg} / \mathrm{kg}$ of freshly prepared alloxan monohydrate. After 72 hours of alloxan injection, fasting blood glucose was tested to confirm diabetes mellitus. After 3 weeks, the animals were anaesthetized and sacrificed to collect blood samples for renal function analysis. The creatinine, urea, and blood urea nitrogen values of Group II were significantly different from those of Group I and Group III at $P<0.001$. Also, there was significant difference $(P<0.05)$ in total protein value between Group II $(4.42 \pm 0.47 \mathrm{mg} / \mathrm{dL}) \mathrm{and} \mathrm{Group}$ I $(5.78 \pm 0.12 \mathrm{mg} / \mathrm{dL})$ as well as Group III $(5.86 \pm 0.19 \mathrm{mg} / \mathrm{dL})$, but there was no significant difference between that of Group I and Group III ( $5.78 \pm 0.12 \mathrm{mg} / \mathrm{dL}$ and $5.86 \pm 0.19 \mathrm{mg} / \mathrm{dL}$, resp.). Thus, VCO is effective in preventing renal damage in diabetic patients.

\section{Background}

Diabetes is a metabolic disease caused by excess glucose in the blood and is characterized by hyperglycemia resulting from defects in insulin secretion, action, or both [1]. In diabetes, the level of glucose is persistently raised above normal range (80-100) mg/dL. Untreated diabetes mellitus causes various histopathological changes in different organs $[2,3]$ and incidences of diabetic nephropathy and renal dysfunction are on the increase [4-6].

Renal dysfunction is the reduced capacity of the kidney to excrete metabolic products which accumulate in the body system and can be detected via renal function test.

Therefore, due to numerous degenerative effects of untreated diabetes mellitus on human system, numerous researches have been carried out and still ongoing for the management and treatment of diabetes mellitus.

Management of diabetes mellitus usually involves adjustment of the diet of the individual, exercise at regular interval, health education, measurement of blood glucose level on a regular level, and, in case of insulin dependent diabetes mellitus (IDDM), supplementary therapy with insulin.

However, recent studies have shown that virgin coconut oil (VCO) has varied degree of beneficial properties such as antiviral, antibacterial, anti-fungal, anti-inflammatory, antidiabetic, antiobesity, antiulcerogenic, analgesic and antipyretic, and antioxidant properties [7, 8]. All these beneficial properties of virgin coconut oil as a result of its active constituents might have a remedial effect on renal dysfunction in diabetes mellitus. Therefore, since renal dysfunction has been on increase in diabetic patients without a promising remedy, this study was carried out to determine whether dietary intake of VCO will protectively or effectively manage renal dysfunction via examination of renal function parameters such as serum creatinine, serum urea, blood urea nitrogen (BUN), and serum total protein estimation in diabetic rats. 


\section{Materials and Methods}

\subsection{Plants}

2.1.1. Preparation of Virgin Coconut Oil (VCO). Dry coconuts were purchased from Gakem, Okuku, and Bekwarra markets in the northern part of Cross River State, Nigeria. The nuts were broken manually; its meat was scrapped from the shell and cut into small piece using a sharp paring knife. The cut pieces were grinded in a grinding machine into viscous slurry and, thereafter, squeezed through cheese cloth to obtain coconut milk which was put into glass jars. The glass jars containing the squeezed coconut milk were left for at least 24 hours to allow the coconut milk and oil to separate into a layer of curd which appears at the top of the jars. The jars were refrigerated for 48 hours so that the curd could harden. Thereafter, the curd was scooped out and discarded leaving the pure virgin oil in the jars. The obtained VCO was decanted into a bottle with a plastic screw cap and stored at room temperature for use in the present study.

However, the preparation of the $10 \%$ virgin coconut oil diet was done by mixing and mashing $100 \mathrm{~g}$ of virgin coconut oil with $900 \mathrm{~g}$ of normal rat chow until there was homogeneity.

The preparation of the $10 \%$ virgin coconut oil meal was done on regular demand [9].

2.2. Experimental Animals. Fifteen (15) male albino Wistar rats weighing 200-250 g were used in this study. The rats were purchased at the animal house of the Department of Human Physiology, Faculty of Basic Medical Sciences, Cross River University of Technology (CRUTECH), Okuku Campus, Nigeria. The animals were kept in cages with suitable temperature, humidity, water, and normal rat chow for 2 weeks to acclimatize.

2.3. Induction of Diabetes Mellitus. The animals were weighed and injected via intraperitoneal route with $150 \mathrm{mg} / \mathrm{kg}$ of alloxan (Sigma) dissolved in normal saline [10].

2.4. Assessment of Blood Glucose Level. Diabetes mellitus was confirmed after 72 hours of alloxan injection by testing the fasting blood glucose levels using Accu-Check Active glucometer and glucose test strip. The accuracy of the test result was confirmed by the use of glucose test kit.

2.5. Experimental Procedure. This work was carried out on 3 groups of rats which comprise 2 control groups (normal and diabetic controls) and 1 test group (diabetic rats fed with $10 \%$ virgin coconut oil); each group contained 5 rats and they were placed in different cages for proper identification. However, all experiments on the animals were carried out in absolute compliance with ethical guideline for research, care, and use of laboratory animals.
2.5.1. Group I: Normal Control. The animals in this group served as control and were fed on normal rat chow and water ad libitum for 3 weeks.

2.5.2. Group II: Diabetic Control. The animals were injected intraperitoneally with $150 \mathrm{mg} / \mathrm{kg}^{-1}$ of alloxan to induce diabetes mellitus. The animals were also fed on normal rat chow and water ad libitum for 3 weeks after diabetes induction.

2.5.3. Group III: Diabetic Rats Fed on Virgin Coconut Oil Diet. Also, each animal in this group was injected intraperitoneally with $150 \mathrm{mg} / \mathrm{kg}^{-1}$ of alloxan. The animals were fed on $10 \%$ virgin coconut oil diet and water ad libitum for 3 weeks.

2.6. Blood Sample Collection. At the end of the 3 weeks of feeding the animals, the animals were anaesthetized with chloroform and $5 \mathrm{~mL}$ syringe was used to collect blood samples into test tubes through cardiac puncture method. The bloods in the test tubes were centrifuged at 3000 revolutions for 10 minutes to obtain serum for specific renal function analysis such as serum creatinine, serum urea, blood urea nitrogen (BUN), and serum total protein.

2.7. Renal Function Analysis. Creatinine, urea, blood urea nitrogen, and total protein were evaluated with commercially available kits from Randox Laboratories Limited (United Kingdom) via spectrophotometry.

\section{Results}

The results obtained were presented as the mean \pm standard error of mean (SEM) and analysed using analysis of variance (ANOVA) with post hoc test (LSD, least significant differences) through Statistics Package for the Social Sciences (SPSS) version 17. The results were considered significant from $P<0.05$.

3.1. Effect of VCO on Creatinine Value. In Figure 1, the creatinine values of normal control group, diabetic control group, and diabetic fed with VCO group were $0.76 \pm 0.04 \mathrm{mg} / \mathrm{dL}$, $3.14 \pm 0.05 \mathrm{mg} / \mathrm{dL}$, and $1.40 \pm 0.02 \mathrm{mg} / \mathrm{dL}$, respectively. The mean value of diabetic control group showed a significant $(P<0.001)$ increase in creatinine value when compared to normal control group and diabetic fed with VCO. Also, a significant $(P<0.001)$ increase in creatinine value in diabetic fed with VCO group was observed when compared to the normal control group.

3.2. Effect of VCO on Urea Value. Figure 2 showed the urea value of normal control group, diabetic control group, and diabetic fed with VCO group $(38.67 \pm 1.48 \mathrm{mg} / \mathrm{dL}, 75.11 \pm$ $0.64 \mathrm{mg} / \mathrm{dL}$, and $59.65 \pm 0.60 \mathrm{mg} / \mathrm{dL}$, resp.). The urea value of diabetic control group significantly increased $(P<0.001)$ when compared to the normal control group and diabetic fed with VCO group. Also, there was significant increase $(P<$ 0.001 ) in urea value of diabetic fed with VCO group when 


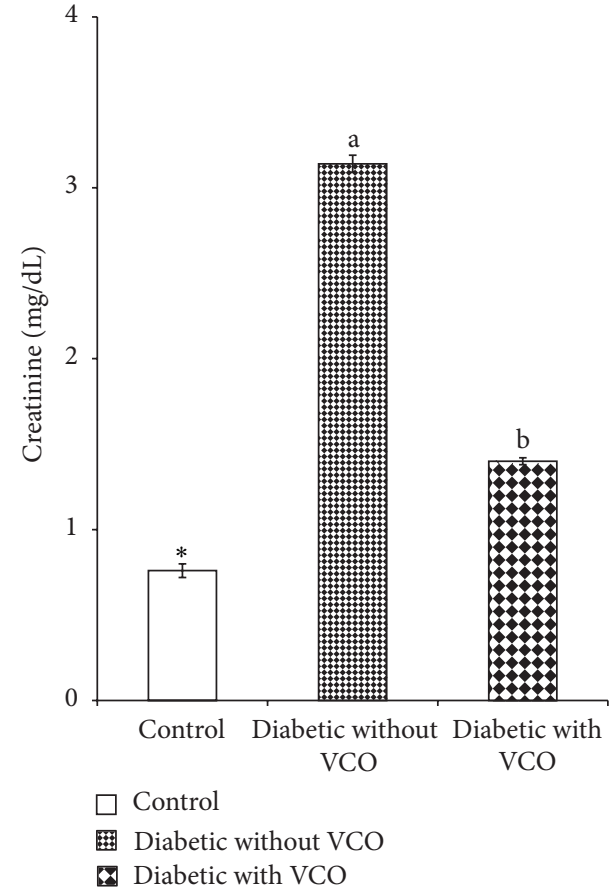

FIGURE 1: Chart showing creatinine level of control and diabetic group with or without virgin coconut oil (VCO). ${ }^{a}$ Significantly different from control group $(P<0.001)$. ${ }^{\mathrm{b}}$ Significantly different from diabetic without VCO $(P<0.001)$. ${ }^{*}$ All the error bars are SEMs.

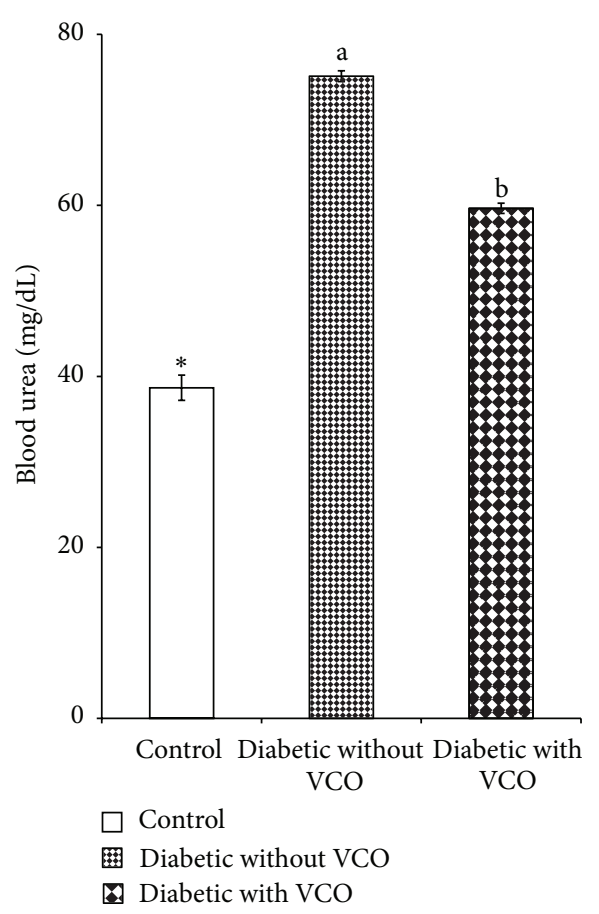

Figure 2: Chart showing blood urea levels of control and diabetic groups with or without virgin coconut oil (VCO). ${ }^{a}$ Significantly different from control group $(P<0.001)$. ${ }^{\mathrm{b}}$ Significantly different from diabetic without VCO $(P<0.001)$. ${ }^{*}$ All the error bars are SEMs.

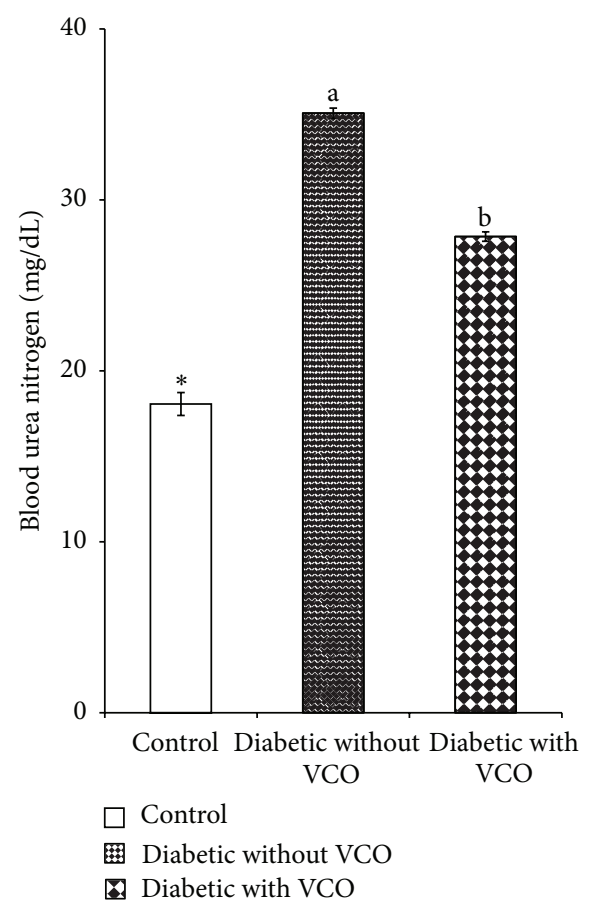

FIgURE 3: Chart showing blood urea nitrogen (BUN) levels of control and diabetic groups with or without virgin coconut oil (VCO). ${ }^{a}$ Significantly different from control group $(P<0.001)$. ${ }^{\mathrm{b}}$ Significantly different from diabetic without VCO $(P<0.001) .{ }^{*}$ All the error bars are SEMs.

compared to normal control group $(59.65 \pm 0.60 \mathrm{mg} / \mathrm{dL}$ and $38.67 \pm 1.48 \mathrm{mg} / \mathrm{dL}$, resp.).

3.3. Effect of VCO on Blood Urea Nitrogen (BUN). In Figure 3, blood urea nitrogen of normal control group, diabetic control group, and diabetic fed with VCO group was $18.06 \pm$ $0.67 \mathrm{mg} / \mathrm{dL}, 35.07 \pm 0.30 \mathrm{mg} / \mathrm{dL}$, and $27.85 \pm 0.28 \mathrm{mg} / \mathrm{dL}$, respectively. The value of diabetic control group was significantly higher $(P<0.001)$ when compared to normal control group and diabetic fed with VCO group. Also, a significant increase in BUN value of diabetic fed with VCO group was observed when compared to normal control group (27.85 \pm $0.28 \mathrm{mg} / \mathrm{dL}$ and $18.06 \pm 0.67 \mathrm{mg} / \mathrm{dL}$, resp.). In addition, a significant difference was observed between diabetic fed with VCO group and diabetic control group, $27.85 \pm 0.28 \mathrm{mg} / \mathrm{dL}$ and $35.07 \pm 0.30 \mathrm{mg} / \mathrm{dL}$, respectively.

3.4. Effect of VCO on Total Protein. In Figure 4, the value of diabetic control group $(4.42 \pm 0.14 \mathrm{mg} / \mathrm{dL})$ showed a significant decrease in protein value when compared to normal control group $(5.78 \pm 0.12 \mathrm{mg} / \mathrm{dL})$ and diabetic fed with VCO group $(5.86 \pm 0.19 \mathrm{mg} / \mathrm{dL})$ at $P<0.05$. There was no significant difference $(P<0.05)$ in total protein value of diabetic fed with VCO group when compared to normal control group, $5.86 \pm 0.19 \mathrm{mg} / \mathrm{dL}$ and $5.78 \pm$ $0.12 \mathrm{mg} / \mathrm{dL}$, respectively. Also, a significant difference was observed between diabetic fed with VCO group and diabetic control group, $5.86 \pm 0.19 \mathrm{mg} / \mathrm{dL}$ and $4.42 \pm 0.47 \mathrm{mg} / \mathrm{dL}$, respectively. 


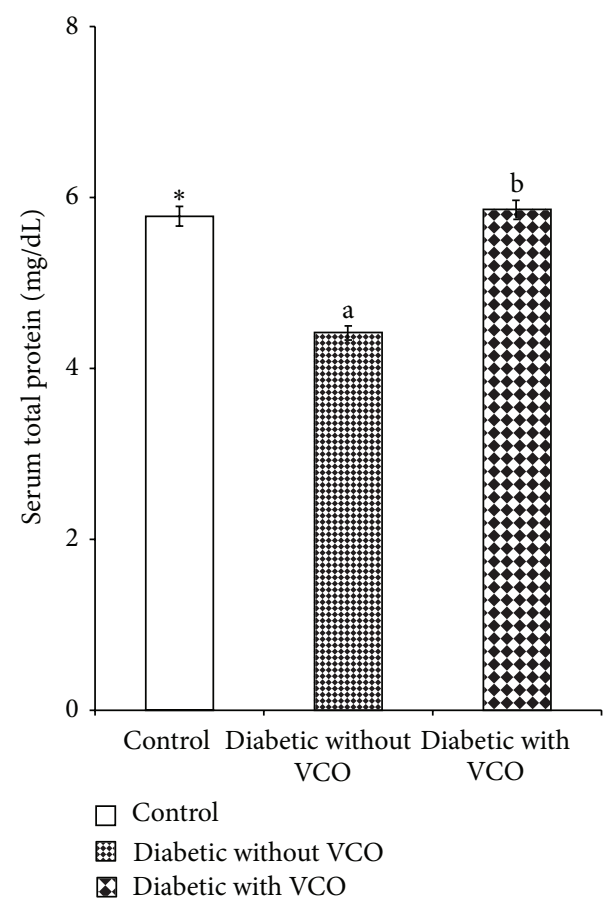

FIgURE 4: Chart showing serum total protein levels of control and diabetic groups with or without virgin coconut oil (VCO). ${ }^{\mathrm{a}}$ Significantly different from control group $(P<0.05)$. ${ }^{\mathrm{b}}$ Significantly different from diabetic without VCO $(P<0.05)$. * All the error bars are SEMs.

\section{Discussion}

Renal dysfunction as a result of diabetes mellitus can be assessed by serum creatinine, urea, BUN, and total protein. Therefore, this suggested that there is strong relationship between these parameters and renal dysfunction. Thus, an increase in creatinine, urea, and BUN occurs when there is renal dysfunction or damage. The increment in serum creatinine, urea, and BUN observed in this study clearly indicated that diabetes mellitus causes damage or dysfunction of the kidney in diabetics. Hence, the results of this study were in accordance with various studies which showed raised serum creatinine, urea, and BUN levels in diabetic patients $[11,12]$. Also, in this study, there were increased levels of these kidney function parameters (except total protein) in diabetic control group when compared to normal control and diabetic test group. The increment observed in diabetic control group revealed that untreated diabetes mellitus caused severe dysfunction of the kidney compared to treated diabetes mellitus through dietary consumption of virgin coconut oil.

According to previous research $[13,14]$, coconut water and coconut milk were reported to have renoprotective and regenerative effects on the kidney and pancreas of diabetic rats; therefore, it is not unreasonable to suggest that virgin coconut oil has remedial and protective effects on the kidneys of diabetic rats like coconut water and coconut milk.

However, the remedial effect of virgin coconut oil may probably be due to the earlier reported antioxidant and antiinflammatory properties of virgin coconut oil as a result of its chemical components especially medium chain fatty acid such as lauric acid $[7,8,15]$.

In addition, in this study, it was observed that there was a decrease in serum total protein of diabetic control group compared to normal control and diabetic test group. This was probably because of the damaging effects diabetes mellitus has on the kidney tissues of diabetic control group which was minimized in diabetic test group as a result of dietary consumption of virgin coconut oil.

In conclusion, this present study showed that diabetes mellitus has degenerating and destructive effects on the kidneys which can lead to renal dysfunction but can be significantly reversed by dietary consumption of virgin coconut oil.

\section{Conflict of Interests}

The authors declare that there is no conflict of interests regarding the publication of this paper.

\section{References}

[1] The American Diabetic Association (ADA), "Standard of medical care in diabetes," Diabetes Care, vol. 1, pp. 515-535, 2004.

[2] E. Harold, Clinical Anatomy, Black Well Scientific Publication, 1978.

[3] P. K. Thomas, "Diabetic peripheral neuropathy: their cost to the patient and society and the value of knowledge of risk factor for the development of interventions," European Neurology, vol. 41, pp. 35-43, 1999.

[4] S. O. Adewole, E. A. Caxton-martins, and J. A. O. Ojewole, "Histochemical and biochemical effect of melatonin on pancreatic cells," Pharmacology, vol. 2, pp. 1-21, 2006.

[5] A. L. Carrington and J. E. Litchfield, "The aldose reductase pathway and non enzymatic glycation in the pathogenesis of diabetic neuropathy: a critical review for the end of 20th century," Diabetes Reviews, vol. 7, pp. 275-299, 1999.

[6] R. S. Clements and D. S. H. Bell, "Diabetic neuropathy: peripheral and authonomic syndrome," in Diabetic Neuropathy, vol. 71, pp. 50-67, 1982.

[7] S. Intahphuak, P. Khonsung, and A. Panthong, "Antiinflammatory, analgesic, and antipyretic activities of virgin coconut oil," Pharmaceutical Biology, vol. 48, no. 2, pp. 151-157, 2010.

[8] Z. A. Zakaria, M. N. Somchit, A. M. Mat Jais, L. K. Teh, M. Z. Salleh, and K. Long, "In vivo antinociceptive and antiinflammatory activities of dried and fermented processed virgin coconut oil," Medical Principles and Practice, vol. 20, no. 3, pp. 231-236, 2011.

[9] M. I. Akpanabiatu, I. B. Umoh, E. O. Udosen, A. E. Udoh, and E. E. Edet, "Rat serum electrolytes; lipid profile and cardiovascular activity on Nauclea latifolia leaf extract administration," Indian Journal of Clinical Biochemistry, vol. 20, no. 21, pp. 29-34, 2005.

[10] T. Szkudelski, "The mechanism of alloxan and streptozotocin action in $\beta$-cells of the rat pancreas," Physiological Research, vol. 50, pp. 536-546, 2001.

[11] A. L. Aldler, R. J. Steven, S. E. Manley et al., "Development and progression of nephropathy in type 2 diabetes: the United Kingdom Prospective Diabetes Study (UKPDS 64)," Kidney International, vol. 63, no. 1, pp. 225-232, 2003. 
[12] T. Judykay, "Nutrition for reducing urea and creatinine in the blood," Diabetes Care, vol. 27, pp. 2191-2192, 2007.

[13] E. K. Nwangwa, "The retino-protective effects of coconut water on the kidneys of diabetic Wistar rats," Journal of Health Sciences, vol. 2, no. 1, pp. 1-4, 2012.

[14] E. K. Nwangwa and P. A. Chukwuemeka, "Regenerative effects of coconut water and coconut milk on the pancreatic B-cells and cyto architecture in alloxan induced diabetic wistar albino rats," American Journal of Tropical Medicine \& Public Health, vol. 1, no. 3, pp. 137-146, 2011.

[15] F. Bruce, "Scientific Evidence Regarding Coconut Oil. The Coconut Oil Miracle: Where is the Evidence?" 2011, http://www .naturepacific.com/contents/en-us/d252_Scientific_Evidence_ regarding_Coconut_Oil_.html. 

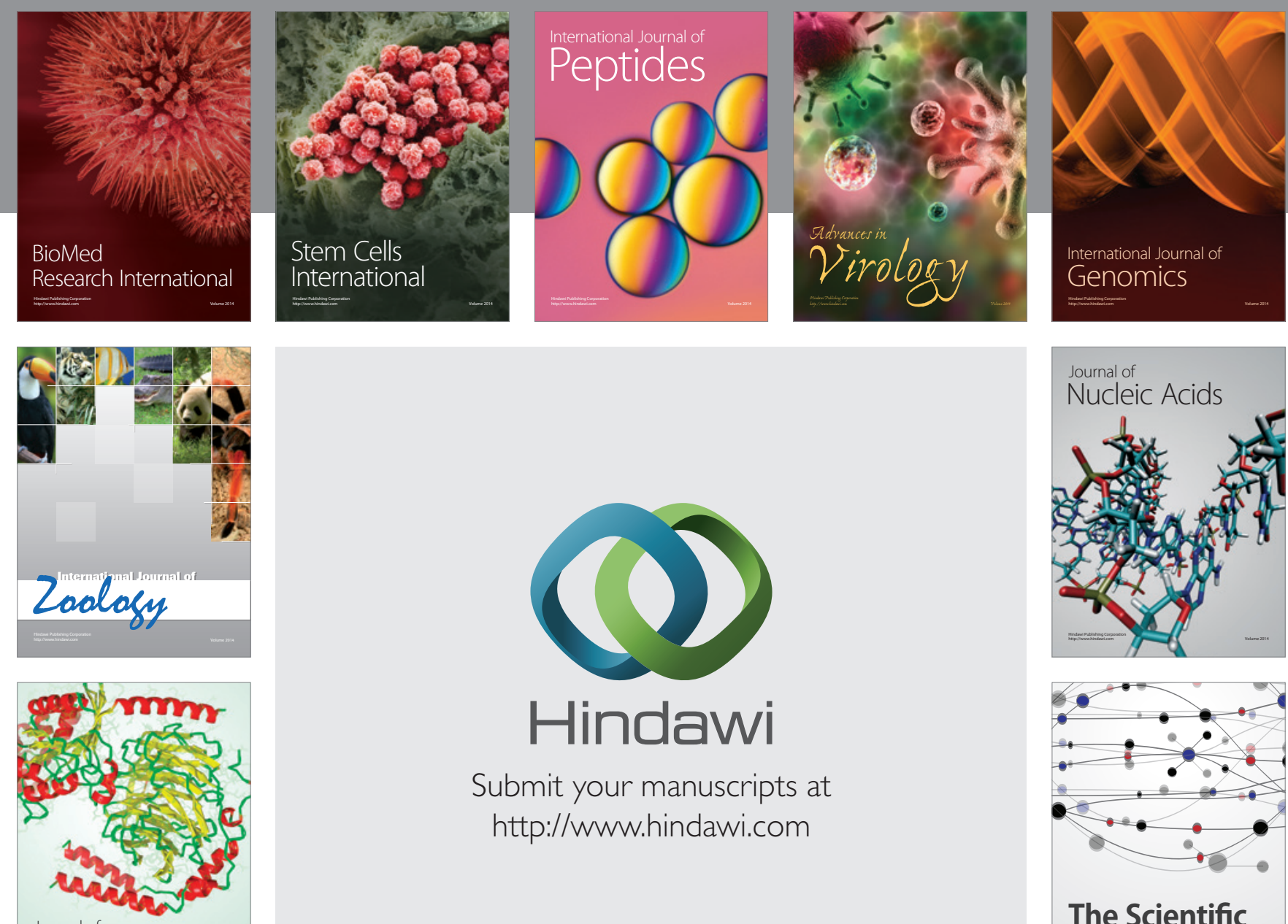

Submit your manuscripts at

http://www.hindawi.com

Journal of
Signal Transduction
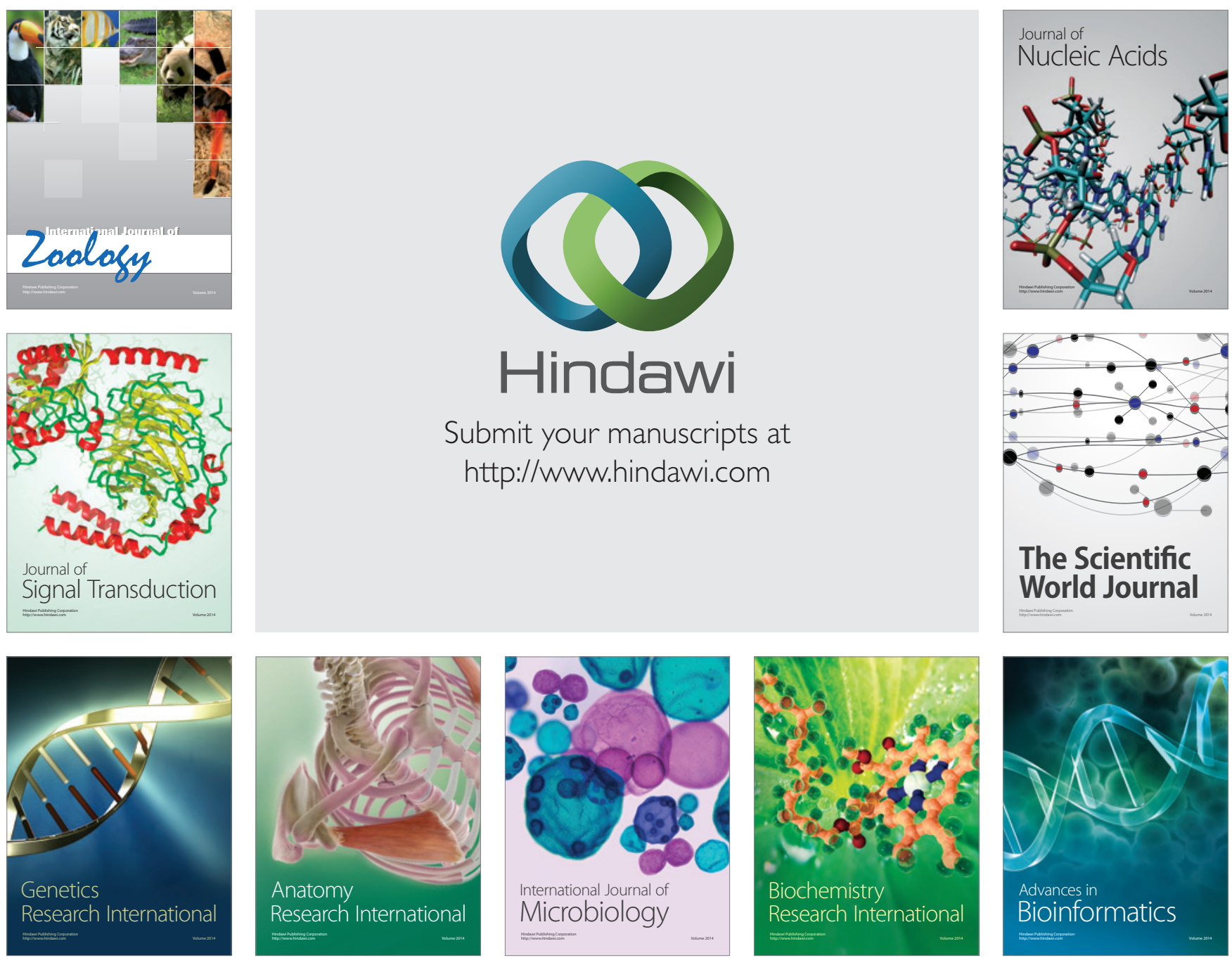

The Scientific World Journal
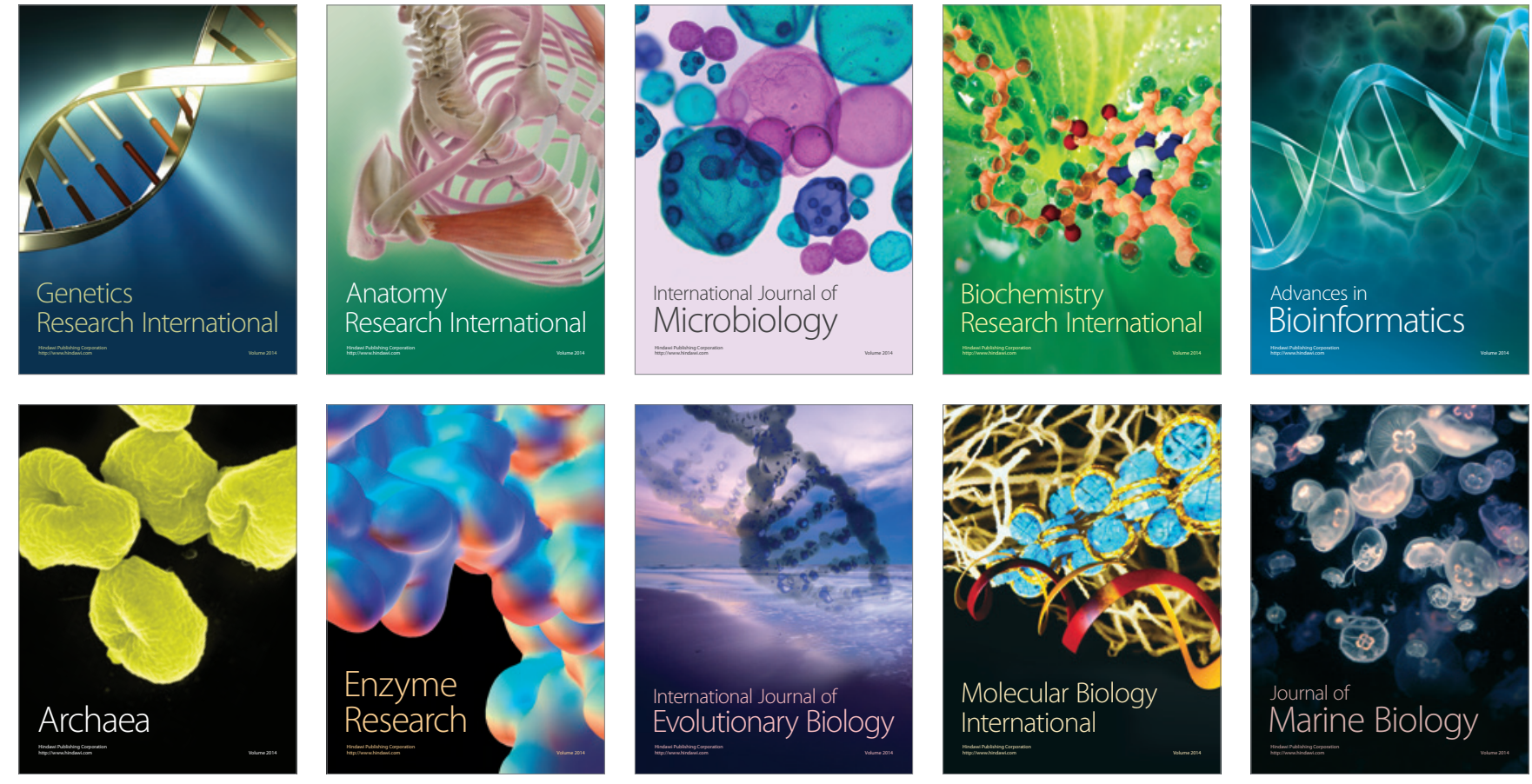